\title{
The Possibility of Using the Brain Imprint in the Criminal Proof in the Iraqi Law
}

\author{
Dr. Khalied Mohammad Ajaj \\ Department of Law/ College of Law/Cihan University/ Sulaimanya
}

\begin{abstract}
The development of scienceledto the existence of a new technique known as discovery ( brain imprint in the field of criminal proof. This kind of imprint can may enable investigators to identify the perpetrators of crimes and works of this new technology to measure and analyze the nature of the electrical activity of the brain at a time less than a second when confronting the owner something aware of it. and if what was presented to the deadly material body of the crime committed and the site does not know one else registers the brain immediately know the way involuntary recorded this technique replies brain acts by electrodes connected to the head to monitor brain activity in the form of electric waves, and the person who was not at the crime scene will not be recorded this technique on the brain of any reactions.
\end{abstract}

\section{INTRODUCTION}

In the past, the courts relied on human testimony only, but modern science came with new aid such as microscopy, electricity and other scientific means., Which led to the overthrow of the Court's mission to a system that leads us to the truth, through scientific devices that can be used and which do not contradict the established work in the introduction of the system of free proof that the judge be a faith of his freedom.( Al Sammak, 1997).This brain imprint is discovered by the American scientist Lawrence Farwell of Fairfield, Iowa, USA in. This fingerprint is based on the persistence of the brain wave P300, which is related to memory and truth detection, and the way the defendant sits in front of a computer screen. The results of the investigation in the form of zigzag lines, and in the case of killing with a tool such as a knife with a blue grip, for example, faced the accused knives in different colors, and note the change at the level of the wave P 300 And once the knife is presented with a blue grip, the memory recall events and raise the graph to the maximum peak in the form of an arc because of the impact of the wave P 300, indicating the relationship with the crime. Therefore, this led to certainty, and to the certainty that this new scientific and technological invention is reasonable evidence before the judiciary(Farwell, L.A. (2013). "In fac,t the Iraqi legislation does not include within its scope the use of these scientific means but it referred implicitly that the use of such modern techniques is possible. as the problem arises regarding the use of these means, can the judge use whatever he wishes of the new procedures such as brainprint in order to reach the truth and on the basis of that must be adopted A clear position in order to reconcile the use of brain imprint as one of the modern scientific means of criminal proof, and the preservation of the rights of individuals and their fundamental freedoms so that we can benefit from the achievements of scientific progress

The importance of the subject to the seriousness and novelty of the issue it deals with and the admissibility of the evidence resulting from modern technology in criminal evidence.

\section{DEFINITION OF BRAIN PRINT}

It is a technique of investigation techniques that helps stimulate cognition by measuring the electric brain wave and how it responds to the words, phrases and images on the computer screen. And brain signals called the p300 information about the crime in the memory MERMER (memory of the internal human), which is recorded and analyzed when retrieving this information by computer.(Farwell LA, Donchin1991). The Truth Will Out: Interrogative Polygraphy ("Lie Detection") With Event-Related Brain Potentials. Thus the real person can be identified. When the suspect is placed in front of a computer screen in front of him an event, such as a word or sentence or crime tool Kalkkin used in the murder and flash before him on the computer screen, the activity of nerve in his brain will be synchronized and will issue an electric wave, and this wave can be measured By placing prototypes, or sensors on the head, and magnifying these devices, this p300 is called the electric wave.(Donchin E, Miller GA, Farwell LA 1986). The development of the use of brain imprint, including the development of the analysis of the brain response to the multi-faceted aspects (electromagnetism known as the MERE and motor and physical terms, as well as progress in the procedures followed in the investigation by practical experiments conducted by scientific scientists in obtaining information, The development of the use of the brain fingerprint in the field of investigation.(Farwell LA, inventor. Method and apparatus for multifaceted 
electroencephalographicresponse analysis (MERA). US patent 1994) .MERMER refers to the electrical response to the memory of the interrogative stimuli related to the subject of the crime, through which the confirmation of the details of the crime in the suspect's brain or it is not present because this response is issued only by the offender.(Farwell LA, Smith SS (2001). brain linked to memory helps to return the information stored in the human brain without feeling that the human brain is issuing a positive charge when identifying something that has.(Farwell, L.A. and Makeig, T.,2005)

\section{THE VIEW OF THE IRAQI LAW OF THE BRAINPRINT}

In this section, a detailed discussion of the view of the Iraqi law concerning the use of the brain print and the and also the view of the Iraqi court concerning the same issue.It is noted that the Iraqi law stated in Article (212) of the Code of Criminal Procedure that "the court may not base its ruling on evidence that was not raised for discussion or was not mentioned in the session or to a paper submitted by one of the litigants, The governor cannot judge the case based on his personal knowledge.well as the text of article 213 / a) of the abovementioned law, which stipulates that: (a) The court shall rule on the case based on its conviction that it has evidence provided in any of the roles of the investigation or trial, namely, recognition, witness testimony, minutes of investigation, Experts, technicians, evidence and other evidence determined by law that the legislator has taken the principle of non-identification of criminal evidence, but it is restricted.

Article (70) of the same above law allowed the investigating judge and the investigator to examine the fingerprints and blood tests and authorized the defendant to be forced to carry out the examination against his will. This can be relied upon as a legitimate legal basis for the Iraqi judge to detect crimes using fingerprints. The Law of Evidence No. 107 of 1979, and in the positive reasons, allowed the court to benefit from scientific progress in the development of evidence. Article 104 of the Iraqi Evidence Law gave the Iraqi judge the right to benefit from the modern methods in science to develop the legal basis, including fingerprints. The means of scientific progress can be used in the process of devising judicial evidence that these means are not at all contrary to human freedom unless they are unequivocal proof. And the question of leaving the discretion of these means to the court of the subject limits the strength of these means. At a time when science has proved the accuracy of these means in evidence. The power of the judge to take the fingerprint of the brain and his passport, he may take or leave it.On the other hand,the judiciary has great importance of in assessing the scientific evidence because of its importance in the modern criminal evidence, whether it takes the principle of self-conviction or mixed doctrine, both give the judge discretion in assessing the evidence before the court, and this leads to two results first is the judge's freedom to accept evidence, That the evidence is subject to the absolute discretion of the judge, that is, the judge can build his self-confidence and his freedom to appreciate the evidence and establish his judgment on any element of proof.(Fouda, 1998.)

\section{CONCLUSION}

The Iraqi criminal legislation has pointed to the use of some scientific means fingerprint as in Article (70) of the origins of Iraqi criminal trials. But did not refer to other means such as brain imprint, but the judiciary turned to the use of scientific means to reach the results in the stage of inference and investigation. Although Article 70 of the Code of Criminal Procedure refers to the fingerprinting, the judiciary in Iraq tends not to be considered alone as a sufficient evidence of conviction, but to rely on it in further evidence. The judge has discretionary power when the expert's report is submitted to him to prove or deny the charge.The Iraqi judiciary has to use modern means of science which have a large and effective role in detecting and limiting crime, as well as the preventive role played by some of these means in detecting the crime before it occurred. The evidence derived from modern scientific methods must be legitimate and the evidence should not be considered null and void. If the evidence obtained does not constitute an attack on the freedom of individuals and does not jeopardize the life of any individual, it may be legitimate to uncover the crime.

\section{BIBLIOGRAPHY}

[1] 1-Ahmed Habib Al Sammak, The Evidence System in Shari'a and Positive Law, Journal of Law, published by the Scientific Publishing Council, Kuwait University, Second Issue, 1997, p. 152.

[2] 2- (Farwell, L.A. (2013). "Lie Detection" in Encyclopedia of Forensic Sciences, Second Edition, J.A. Siegel and P.J. Saukko, eds, pp. 144-149. Waltham: Academic Press.)

[3] 3- Farwell LA, Donchin E (1991). The Truth Will Out: Interrogative Polygraphy ("Lie Detection") With Event-Related Brain Potentials. Psychophysiol., 28: 531-547.

[4] (Donchin E, Miller GA, Farwell LA (1986) The endogenous componentsof the event-related potentiala diagnostic tool? In:

[5] Swaab DF, Fliers E, Mirmiran M, Van Gool WA, Van Haaren F(eds) Progress in brain research, vol 70: aging of the brain and 
[6] Alzheimer's disease. Elsevier, Amsterdam, pp 87-102..( Farwell LA, inventor. Method and apparatus for multifaceted electroencephalographic

[7] response analysis (MERA). US patent 5,363,858. 1994, pp: 33-60..( Farwell LA, Smith SS (2001). Using Brain MERMER Testing to Detect Concealed Knowledge Despite Efforts to Conceal. J. Forens. Sci., 46(1): 135-143.

[8] . (Farwell, L.A. and Makeig, T. (2005). "Farwell Brain Fingerprinting in the case of Harrington v. State." Open Court X,3:7-10, Indiana State Bar Assoc.

[9] Dr.. Abdel Hakim Fouda, Author of the Technical Guide in Criminal and Civil Materials, University Thought House, Alexandria, 1998, p. 18.). 